\title{
PILARES DE CONCRETO ARMADO REFORÇADOS POR MEIO DE ENCAMISAMENTO
}

\section{REINFORCED CONCRETE COLUMNS STRENGTHENED USING JACKETING}

\author{
Rafael Crissóstomo de Pádua ${ }^{1}$, Andréa Prado Abreu Reis Liserre ${ }^{2}$, \\ Áureo Ferreira da Silva ${ }^{3}$, Dilene Aires Aguiar ${ }^{4}$
}

Recebido em 27 de outubro de 2012; recebido para revisão em 01 de novembro de 2012; aceito em 04 de novembro de 2012; disponivel on-line em 06 de novembro de 2012.

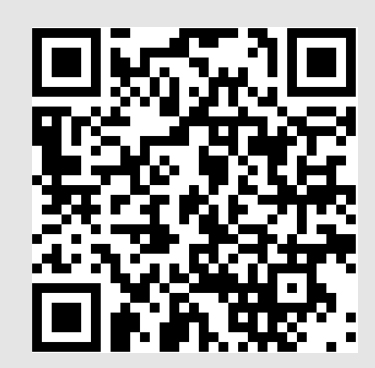

PALAVRAS CHAVES:

Pilar;

Concreto Armado;

Reforço Estrutural;

Encamisamento.

\footnotetext{
* Contato com os autores:

${ }^{1}$ e-mail : rafaelcrissostomo@gmail.com (R. C. de Pádua)

Aluno de Iniciação Científica - Escola de Engenharia Civil - (EEC-UFG)

${ }^{2}$ e-mail : andrea.liserre@gmail.com (A. P. A. R. Liserre)

Professora Dsc. da Escola de Engenharia Civil - (EEC-UFG)

${ }^{3}$ e-mail : aureo.ferreira@ig.com.br (A. F. da Silva)

Mestrando do Curso de Mestrado em Engenharia Civil (CMEC-EEC-UFG)

${ }^{4}$ e-mail : dileneaires@yahoo.com.br (D. A. Aguiar)

Mestrando do Curso de Mestrado em Engenharia Civil (CMEC-EEC-UFG)
} 


\section{INTRODUÇÃO}

Apesar das estruturas em concreto armado serem bastante seguras quando executadas de acordo com as prescrições das normas, falhas de projeto, de execução e até mesmo alterações no uso das edificações podem provocar problemas nas edificações. No caso de pilares, que são os elementos estruturais responsáveis por transportar as ações dos pavimentos da obra para as fundações, qualquer falha em seu funcionamento afetará significativamente o desempenho da estrutura como um todo, podendo até mesmo levá-la a ruína. Para evitar acidentes, é possível reforço dos pilares, mas para isso exige-se que o projetista seja capaz de prever seu comportamento estrutural após a intervenção, a fim de adotar uma solução viável e segura para os usuários da edificação. Entretanto, apesar de existirem várias técnicas de reforço de estruturas de concreto, muitas ainda se baseiam na experiência empírica acumulada, devido ao caráter artesanal e incomum dos processos de reabilitação, uma vez que cada problema enfrentado tem características próprias. Além disto, em muitos casos não existe uma metodologia específica de análise do comportamento estrutural da peça reabilitada, nem diretrizes que orientem o projetista no redimensionamento e reprojeto.

Visando contribuir para uma melhor compreensão do comportamento estrutural das estruturas reabilitadas, o presente trabalho teve como objetivo geral o estudo de pilares de concreto armado reforçados por meio de encamisamento, aumentando-se as dimensões da seção transversal da peça, adicionandose uma nova camada de concreto que pode ou não envolver novas armaduras. Com relação aos objetivos específicos optou-se por:

- Fazer um levantamento dos principais trabalhos realizados sobre o comportamento estrutural de pilares de concreto armado reforçados por encamisamento, a fim de identificar as lacunas de conhecimento sobre o desempenho deste tipo de estrutura;

- Comparar o comportamento experimental de pilares reforçados por encamisamento com o comportamento teórico baseado em normas vigentes;

- Verificar como o tipo de rugosidade da superfície de contato, e a presença de conectores metálicos cruzando a interface de ligação influenciam na aderência entre os concretos.

\section{REVISÃO BILIOGRÁFICA}

\subsection{ADERÊNCIA ENTRE CONCRETOS MOLDADOS EM} IDADES DISTINTAS

Existem várias técnicas de reabilitação de estruturas de concreto armado, dentre elas pode-se citar: a protensão externa, a adição de chapas ou perfis metálicos, o uso de materiais compósitos tais como fibras de carbono, e a adição de concreto com ou sem aço à seção transversal do elemento. Essa última técnica, também conhecida por encamisamento da seção, é relativamente simples, pois usa os materiais mais comuns da construção civil, que são o aço e o concreto. Isso faz com que o custo da reabilitação seja bastante competitivo quando comparado a outras técnicas, sendo uma das mais utilizada no Brasil. Este reforço é muito empregado devido às suas vantagens econômicas e facilidade na execução. Porém, produz elementos finais de dimensões superiores às iniciais, e exige um tempo de espera para que o reforço atinja a resistência conveniente antes da liberação das ações na parte estrutural reforçada.

O reforço de pilares pode ser feito a partir do aumento de sua seção transversal com concreto de resistência adequada e com a utilização de armaduras longitudinais e transversais adicionais. O acréscimo de seção não precisa ser feito em todo contorno do pilar, podendo ser feito em apenas algumas faces, ou seja, este tipo de reforço pode envolver total ou parcialmente a seção original da estrutura existente. A Figura 1 ilustra as várias configurações de encamisamento que podem ser adotadas no reforço de um pilar dependendo: da posição, das condições de acesso, da patologia e da carga a ser suportada pelo pilar (TAKEUTI, 1999).

Para garantir que a peça reabilitada se comporte monoliticamente, geralmente adota-se armaduras que atravessam a interface entre os concretos, para resistir ao cisalhamento que ali se desenvolve. Essas armaduras podem ser representadas por estribos prolongados, chumbadores, ou barras/pinos fixados com resinas.

Uma das maiores preocupações nos reforços por encamisamento é garantir que a peça volte a trabalhar como se fosse monolítica. Isso depende essencialmente da aderência existente entre o novo material adicionado e o concreto original da peça (substrato). A deficiência desta propriedade pode comprometer o desempenho global do sistema, e deve ser analisada por meio do estudo da transferência de esforços tangenciais em interfaces formadas por concretos moldados em idades distintas.

Como a avaliação da aderência entre o reforço e o substrato é um dos objetivos deste trabalho, descrevese a seguir, a maneira como a transferência de esforços é feita e os principais fatores que interferem neste parâmetro. No caso, a transmissão de esforços entre juntas ocorre de duas maneiras distintas: 
- $\quad$ por meio da superfície de contato entre materiais cimentícios;

- $\quad$ por meio de armadura cruzando a interface.

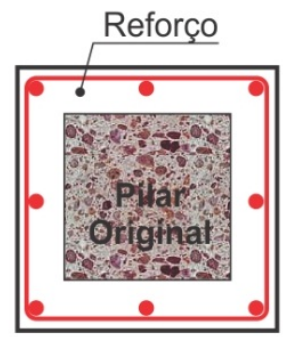

Reforço em todo o contorno do pilar

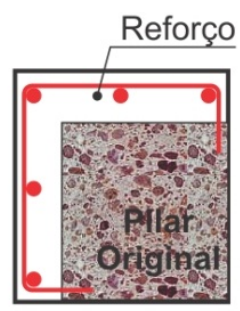

Reforço em duas faces do pilar

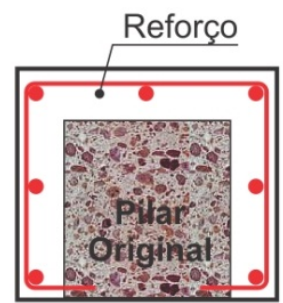

Reforço em três faces do pilar

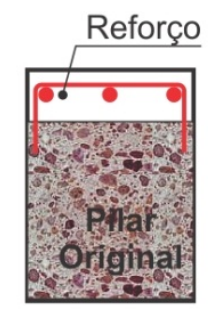

Reforço em uma face do pilar
Figura 1: Tipos de configurações de reforço de pilares (TAKEUTI, 1999).

A transferência por meio da superfície de contato entre materiais cimentícios é subdividida em três parcelas: adesão, atrito e ação mecânica. A adesão ocorre devida a absorção capilar, em que as partículas do concreto novo são gradualmente confinadas nos poros capilares do concreto velho. Com a hidratação do concreto novo há um enlace físico desse com as irregularidades do concreto velho. Este tipo de aderência é a primeira a ser solicitada, mas é destruída para pequenos deslocamentos. $O$ atrito começa a ser solicitado imediatamente após o rompimento da adesão, sendo influenciado pela rugosidade da superfície, tamanho dos agregados e resistência do concreto. A ação mecânica surge devido ao engrenamento mecânico dos agregados, transferindo, diretamente, tensões normais e cisalhantes. Segundo CARASEK (1996), para uma argamassa de reparo rica em aglomerante, bastante fluida e pouco coesa, o gel cimentício penetra facilmente pelos poros e cavidades do substrato, formando uma profunda ancoragem. Porém, no caso de excesso ou perda de água da interface com o substrato poroso, as camadas da argamassa mais próximas ao substrato tornam-se extremamente porosas, gerando falhas de aderência que podem comprometer o reforço. A aderência do material de reforço ao substrato também é afetada pelo índice de retração da argamassa, influenciado pela relação água/cimento, finura do agregado miúdo e das adições usadas e está, intimamente, relacionado às condições ambientais de exposição do reforço. Esta retração pode ocorrer devido à falta de molhagem do substrato de concreto e de condições ambientais agressivas, devido à temperatura ou ventos.

Pode-se dizer, portanto que a transferência de esforços por meio da superfície de contato se relaciona intimamente com a aplicação de água, nata de cimento ou outra "ponte de aderência" específica para auxiliar a ligação entre o concreto do reforço e o substrato. Certifica-se então que o tratamento realizado na superfície do substrato é de notória importância para a obtenção de uma aderência eficaz.

A transferência de esforços por meio da armadura que cruza a interface pode ser classificada em: efeito pino e efeito costura (confinamento). O efeito pino é mobilizado quando a junta de concreto é solicitada por esforços de cisalhamento que provocam uma tendência de deslizamento entre as partes em contato. Se existir armadura atravessando a interface, esse movimento tenderá a cisalhá-la. A armadura, por sua vez, fornecerá uma resistência ao corte que será somada à resistência fornecida pela superfície de contato. O efeito costura da armadura que cruza a interface contribui na resistência porque aumenta o atrito na interface, pois gera tensões normais que solicitam essas barras de aço. Esta tensão normal surge devido a tendência de separação entre os dois concretos quando há deslizamento relativo, o que provoca tração na armadura, e esta reage comprimindo a superfície, aumentando a parcela de atrito. A Figura 2 mostra as tensões que surgem com o deslizamento relativo na interface.
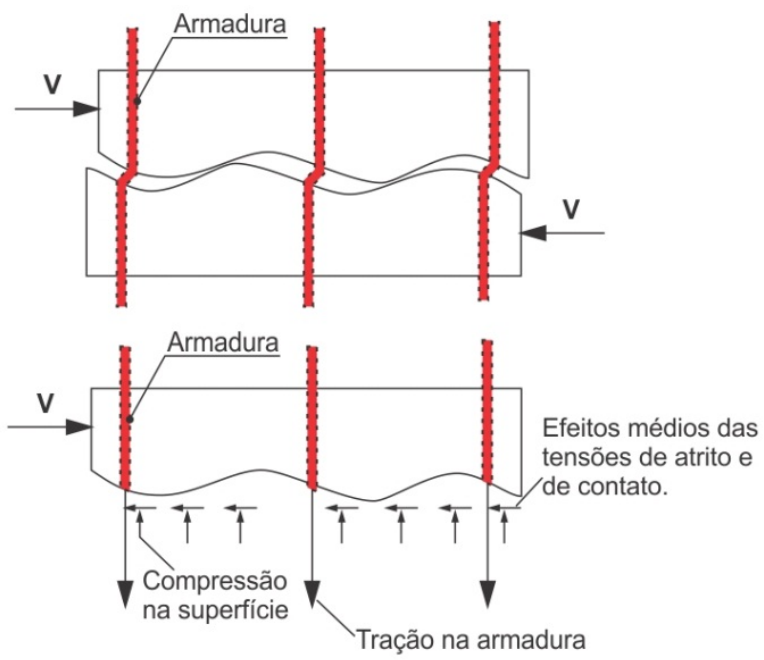

Figura 2: Tensões na interface devido ao deslizamento relativo (ALI e WHITE, 1999). 


\subsection{TRABALHO SOBRE REFORÇO DE PILARES EXECUTADOS POR OUTROS PESQUISADORES}

OMAR (2006), SAHB (2008) e NASCIMENTO (2009) estudaram, por meio de ensaios experimentais, o comportamento de pilares de concreto armado reforçados por encamisamento nas faces de compressão e tração, submetidos à flexo-compressão reta. As características destes pilares estão nas Figuras 3 e 4.

OMAR (2006) ensaiou oito pilares de concreto armado com seção transversal variável em função do tipo de reforço executado (Figura 4). Dois pilares tinham a seção menor (Figura 4a) e representavam as peças antes do reforço, onde existia uma excentricidade de 60 $\mathrm{mm}$. Os outros seis pilares foram reforçados nas faces tracionadas e comprimidas, sendo que a execução destes reforços influenciavam no valor da excentricidade de carga atuante no pilar. Para facilitar a execução do reforço, utilizou-se concreto auto-adensável (CAA), e a escarificação da superfície foi feita usando pontalete manual e martelete pneumático.

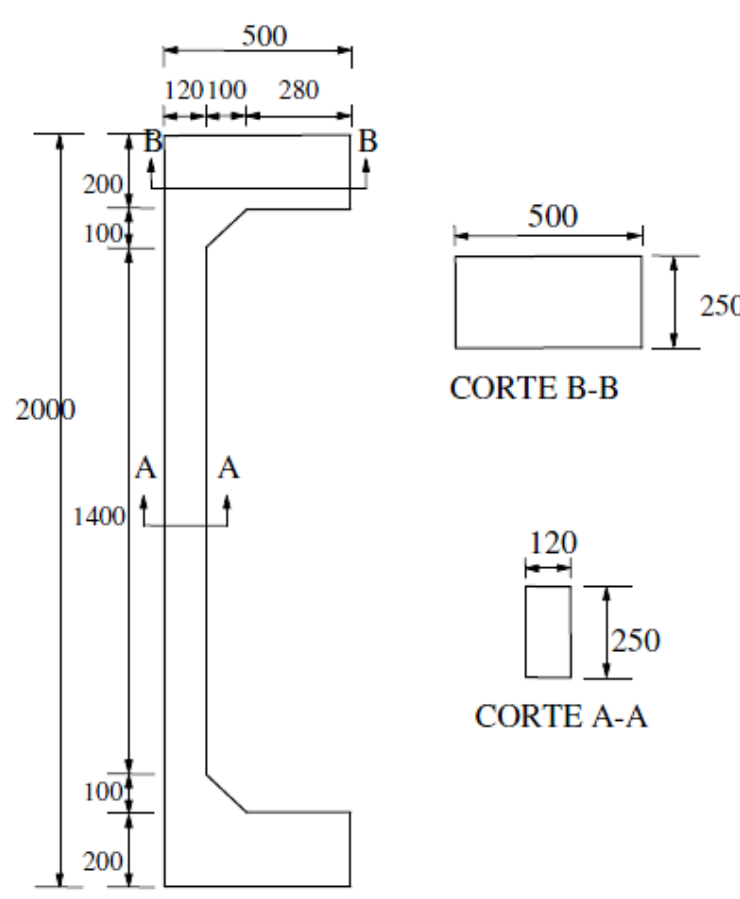

(Obs.: Unidades em milímetros)

a) Características do pilar antes do reforço

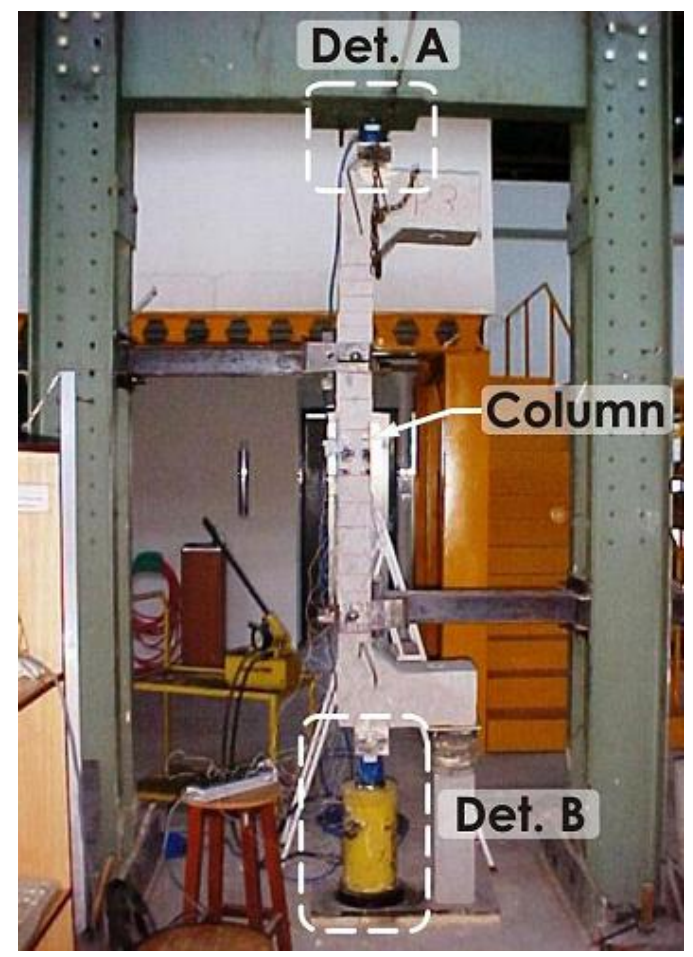

b) Aparato de ensaio

Figura 3: Esquema dos pilares ensaiados por OMAR (2006), SAHB (2008) e NASCIMENTO (2009).

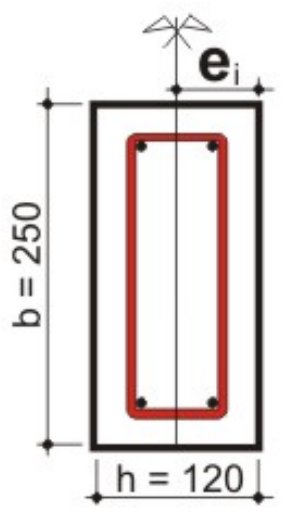

a) Pilar original antes do reforço

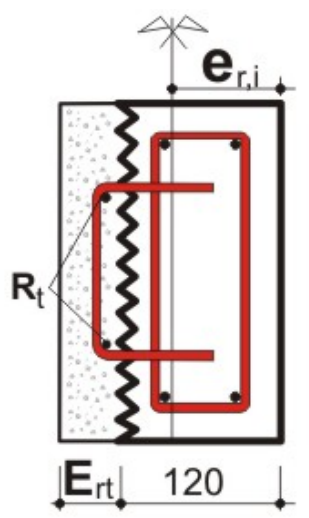

b) Pilar reforçado na face tracionada

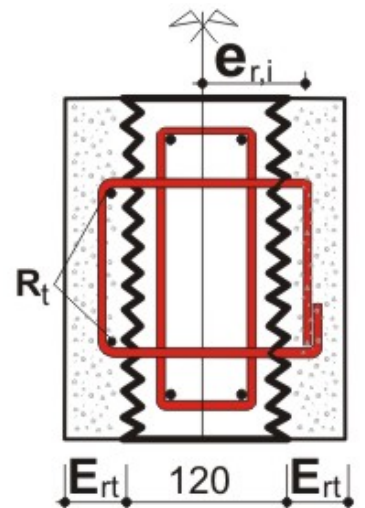

c) Pilar reforçado na face tracionada e comprimida

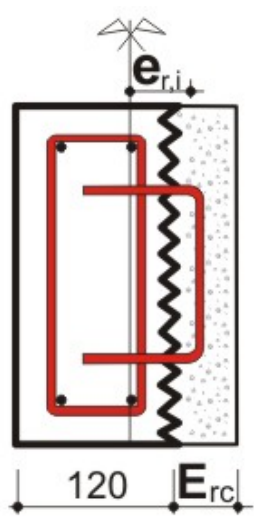

d) Pilar reforçado na face comprimida

Figura 4: Seções das seções transversais dos pilares ensaiados por OMAR (2006). 
Após os ensaios concluiu-se que apesar de se usar novos estribos como conectores para aumentar a resistência da junta, ocorreu desplacamento entre o concreto do substrato e do reforço. Apesar do desplacamento ter surgido apenas em um estágio de carregamento avançado, permitindo que houvesse aumento significativo da capacidade portante do pilar após a execução do reforço, isso indica que ainda há necessidade de mais estudos a respeito dos dispositivos usados para impedir falhas de aderência, a fim de que o engenheiro possa dimensionar adequadamente a armadura de costura durante o projeto de uma intervenção. Em relação ao uso de concreto autoadensável, este se mostrou satisfatório como material de reforço, pois permitiu moldar as peças sem haver segregação nem aparecimento de "brocas". Quanto à aderência, este material trabalhou em conjunto com o substrato, aumentando a capacidade portante das peças reforçadas;

SAHB (2008), para obter maiores informações sobre a influência do tipo de conector de cisalhamento na aderência entre os concretos usados nos pilares reforçados por encamisamento, ensaiou dez pilares semelhantes ao de OMAR (2006). A diferença é que ao invés de usar estribos como armadura de costura, utilizou-se chumbadores metálicos (Figura 5). (d)

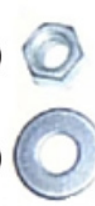

(c)
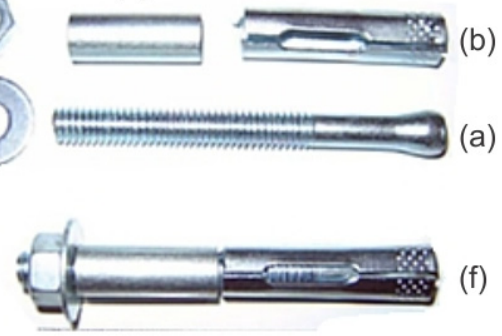

(a) parafuso cônico

(b) jaqueta

(c) prolongador

(d) porca

(e) arruela

(f) parafuso completo

Figura 5: Modelo de chumbador utilizado por SAHB, 2008.

SAHB (2008) concluiu que nenhum conector rompeu por cisalhamento. Entretanto, vários pilares apresentaram uma ruptura prematura devido ao desplacamento entre os concretos do reforço e o substrato. Ao aumentar a taxa de chumbadores, o desplacamento entre os concretos ocorria para um nível de carga maior. Logo, a capacidade portante da peça reforçada aumentava com o aumento do número de conectores utilizados. No pilar com a maior taxa de chumbadores, observou-se inclusive uma tendência de esmagamento do concreto na região central do pilar, apensar de ter ocorrido desplacamento da camada de reforço. Isso evidencia-se que se estava chegando ao valor ideal da taxa de conectores a ser usado nas peças para evitar o desplacamento. Outro fato observado foi que com o acréscimo da taxa de chumbadores houve uma redução de deslocamentos laterais dos pilares, provavelmente em função do aumento da rigidez do elemento.

NASCIMENTO (2009) ensaiou nove pilares reforçados semelhantes aos de OMAR (2006) e SAHB (2008). A diferença consistia no tipo de conector usado para garantir a ligação entre os concretos do substrato e do reforço, que tinha a forma de um estribo aberto, e era colocado dentro de um sulco no pilar (Figura 6).

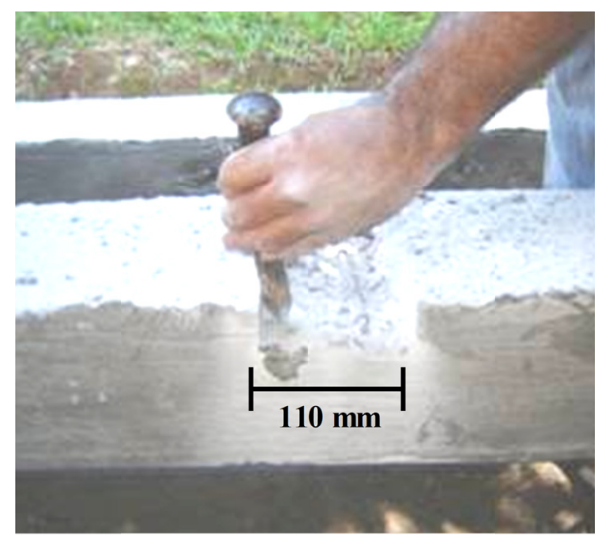

(a) Abertura do sulco

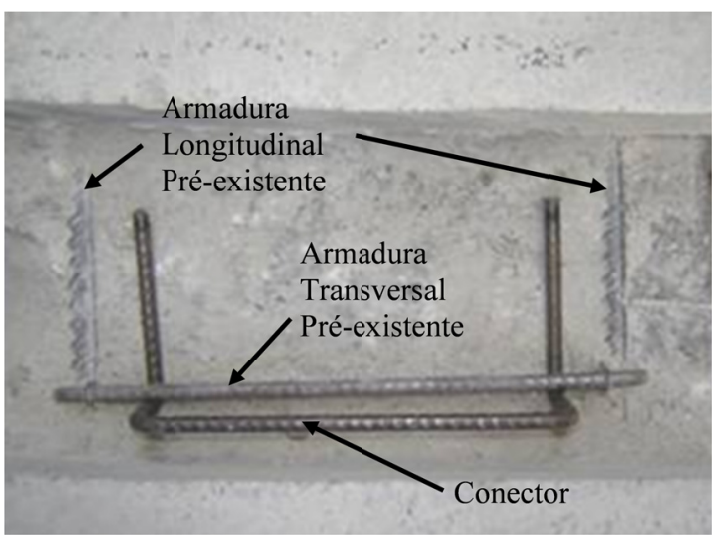

(b) Fixação do conector metálico no sulco

Figura 6: Procedimento para garantir união entre os concretos da peça reforçada (NASCIMENTO, 2009).

Foram utilizados conectores em diferentes posições ao longo da peça com o intuito de identificar qual seriam os melhores locais para se fixar tais conectores a fim de se obter uma ligação satisfatória, favorecendo o trabalho monolítico da peça e evitando a ruptura do pilar pelo desplacamento do reforço. Os 
resultados obtidos indicaram que não só a quantidade, mas principalmente, a localização dos conectores utilizados na ligação entre substrato e reforço, são imprescindíveis para um bom resultado de resistência e modo de ruptura. Por exemplo, reforçar um pilar submetido à flexo-compressão com conectores mais afastados do centro do mesmo possibilita que os valores das cargas de ruptura desejáveis sejam devidamente alcançados, embora não garanta um modo de ruptura seguro. Portanto, é necessário que seja respeitado um espaçamento mínimo entre os conectores do reforço, para garantir a monoliticidade da peça, possibilitando a ocorrência de uma ruptura sem desplacamento por falhas de aderência entre os concretos.

\section{PROGRAMA EXPERIMENTAL}

Foram ensaiados à compressão centrada, 25 pilaretes com $60 \mathrm{~cm}$ de altura, todos com armadura composta por quatro barras longitudinais de aço CA-60, de 5 $\mathrm{mm}$ de diâmetro, e sete estribos distribuídos a cada 9,33 $\mathrm{cm}$, também de aço CA-60 de $5 \mathrm{~mm}$ de diâmetro. Em algumas peças foram usados conectores para melhorar a aderência entre o concreto novo e o concreto do substrato (Figura 6).

Foram ensaiadas peças com seções transversais distintas, e que eram monolíticas ou reforçadas. Vinte e um (21) pilares foram moldados com seção transversal $8 \times 8 \mathrm{~cm}$. Com exceção de um, que representava o pilar monolítico original, todos os demais foram reforçados acrescentandose uma nova camada de concreto de $2 \mathrm{~cm}$ em várias faces da peça. Além desses, foram confeccionadas outras quatro (04) peças monolíticas com seção transversal de $10 \times 8 \mathrm{~cm}$, $10 \times 10 \mathrm{~cm}, 12 \times 10 \mathrm{~cm}$ e $12 \times 12 \mathrm{~cm}$, que juntamente com um dos pilaretes do tipo $8 \times 8 \mathrm{~cm}$, compuseram a série monolítica dos ensaios (Figura 7).

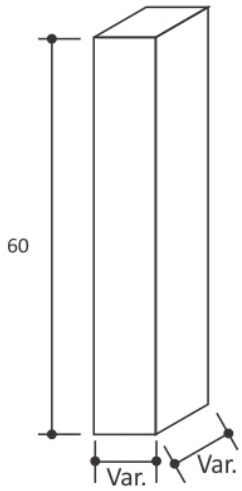

(a) Vista do pilar com seção variável

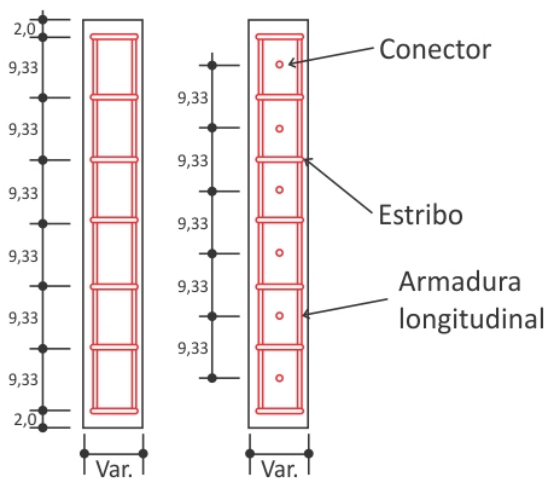

(b) Detalhe das armaduras (Cotas em $\mathrm{cm}$ )
Figura 6: Características dos pilares ensaiados.
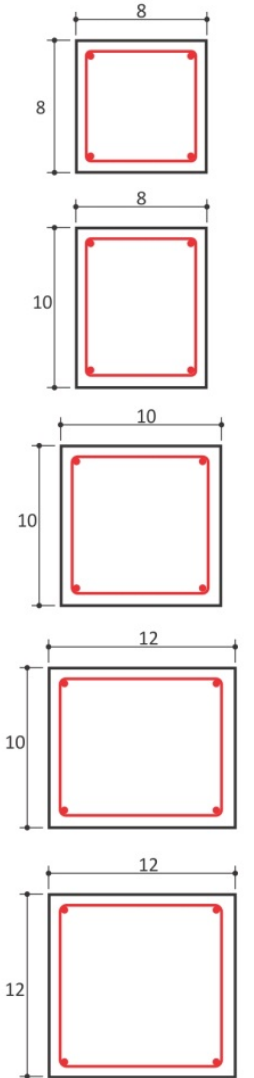

(a) tipos de seções monolíticas (cotas em $\mathrm{cm}$ )
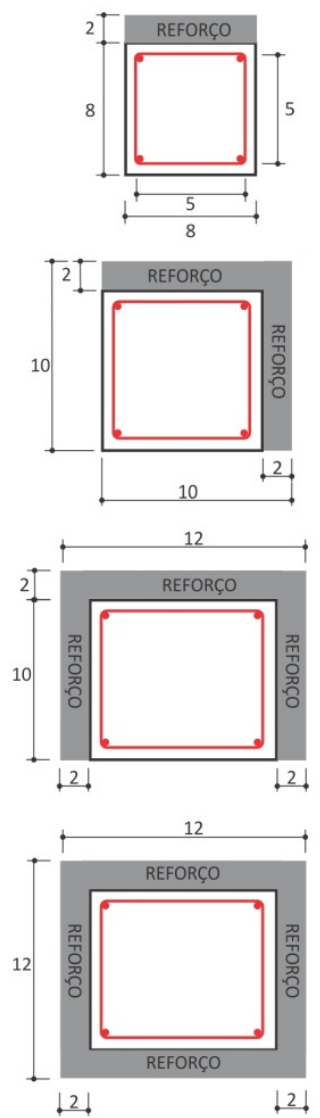

(b) tipos de seções reforçadas (cotas em $\mathrm{cm}$ )

Figura 7: Tipos de seções transversais dos pilares ensaiados

Os pilares ensaiados se diferenciavam em função de dois parâmetros: presença ou não de conectores (armadura de costura) nas faces reforçadas, e tipo de tratamento superficial realizado na junta antes da execução do reforço. Para facilitar a análise dos resultados, os pilares foram subdivididos em seis séries distintas, cujas características estão na Tabela 1.

Nas séries 2 e 3 não foi feito escarificação do substrato antes de se aplicar a camada de reforço. $\mathrm{Na}$ série 5 , o substrato foi escarificado usando um matelete elétrico até expor o agregado graúdo e na série 6 utilizou-se uma serra circular (maquita), que produziu certa rugosidade ao substrato por meio de raspagem da nata de cimento para expor os agregados graúdos. Detalhes da superfície escarificada usando estes equipamentos estão na Figura 8. Nesta figura visualizam-se também os conectores (armadura de costura) dispostos nas faces dos pilaretes a cada $9,33 \mathrm{~cm}$, entre os estribos, feitos a partir de barras de aço de $8 \mathrm{~mm}$ de diâmetro, CA-50. O furo para fixar este conector foi feito usando furadeira elétrica com broca de $10 \mathrm{~mm}$, e tinham profundidade de $1,5 \mathrm{~cm}$. Para fixar os conectores dentro do furo foi utilizado resina epóxi. Antes de concretar o reforço, umedeceu-se a superfície a ser reforçada para garantir melhor adesão entre os concretos. 
Tabela 1: Características de cada uma das séries ensaiadas

\begin{tabular}{|c|c|c|}
\hline Série & Característica das peças & $\begin{array}{c}\text { Nomenclatura usada } \\
\text { para os pilares }\end{array}$ \\
\hline 1 & Pilares monolíticos (peças não reforçadas) & $\begin{array}{c}8 \times 8 \mathrm{MO} \\
10 \times 8 \mathrm{MO} \\
10 \times 10 \mathrm{MO} \\
12 \times 10 \mathrm{MO} \\
12 \times 12 \mathrm{MO}\end{array}$ \\
\hline 2 & Sem tratamento superficial (junta lisa) e sem conectores & $\begin{array}{c}10 \times 8 \text { ST-SC } \\
10 \times 10 \text { ST-SC } \\
10 \times 12 \text { ST-SC } \\
12 \times 12 \text { ST-SC }\end{array}$ \\
\hline 3 & Sem tratamento superficial (junta lisa) e com conectores & $\begin{array}{c}10 \times 8 \text { ST-CC } \\
10 \times 10 \text { ST-CC } \\
10 \times 12 \text { ST-CC } \\
12 \times 12 \text { ST-CC }\end{array}$ \\
\hline 4 & Escarificação com martelete e sem conectores & $\begin{array}{l}\text { 10x8 MART -SC } \\
\text { 10x10 MART -SC } \\
\text { 10x12 MART -SC } \\
12 \times 12 \text { MART -SC }\end{array}$ \\
\hline 5 & Escarificação com martelete e com conectores & $\begin{array}{c}\text { 10x8 MART -CC } \\
\text { 10x10 MART - CC } \\
10 \times 12 \text { MART - CC } \\
12 \times 12 \text { MART - CC }\end{array}$ \\
\hline 6 & $\begin{array}{l}\text { Escarificação com serra circular (maquita) e com } \\
\text { conectores }\end{array}$ & $\begin{array}{l}10 \times 8 \mathrm{MQ}-\mathrm{CC} \\
10 \times 10 \mathrm{MQ}-\mathrm{CC} \\
10 \times 12 \mathrm{MQ}-\mathrm{CC} \\
12 \times 12 \mathrm{MQ}-\mathrm{CC}\end{array}$ \\
\hline
\end{tabular}

O substrato foi concretado utilizando concreto auto-adensável (CAA) utilizando brita zero e o reforço, concretado 90 dias depois, utilizou brita 1 e brita zero. Durante a concretagem, moldou-se corpos-de-prova $15 \mathrm{x}$ $30 \mathrm{~cm}$ para determinar a resistência à compressão e o módulo de elasticidade dos concretos no dia do ensaio. Para o aço, não foi possível realizar ensaios para determinar a tensão de escoamento experimental, adotando-se nos cálculos, a tensão de escoamento convencional para aço CA-60 $(\varnothing=5 \mathrm{~mm})$.

As fôrmas utilizadas (Figura 9a) eram metálicas e tinham $210 \mathrm{~cm}$ por $60 \mathrm{~cm}$, dentro delas foram criadas subdivisões usando placas de madeirite e caibros de maneira a permitir a moldagem do substrato e o reforço dos diversos pilares. $\mathrm{O}$ esquema de ensaio está na Figura $9 b$.

Tabela 2: Estimativa das propriedades dos materiais.

\begin{tabular}{c|c|c|c|c}
\hline \multicolumn{2}{c|}{ Concreto do Substrato } & \multicolumn{2}{c|}{ Concreto do Reforço } & Escoamento do aço \\
\hline$f_{\mathrm{cj}}(\mathrm{MPa})$ & $\mathrm{E}_{\mathrm{cj}}(\mathrm{GPa})$ & $f_{\mathrm{cj}}(\mathrm{MPa})$ & $\mathrm{E}_{\mathrm{cj}}(\mathrm{GPa})$ & $f_{\mathrm{y}}(\mathrm{MPa})$ \\
\hline 48,9 & 36,1 & 62,2 & 31,2 & 600 \\
\hline
\end{tabular}




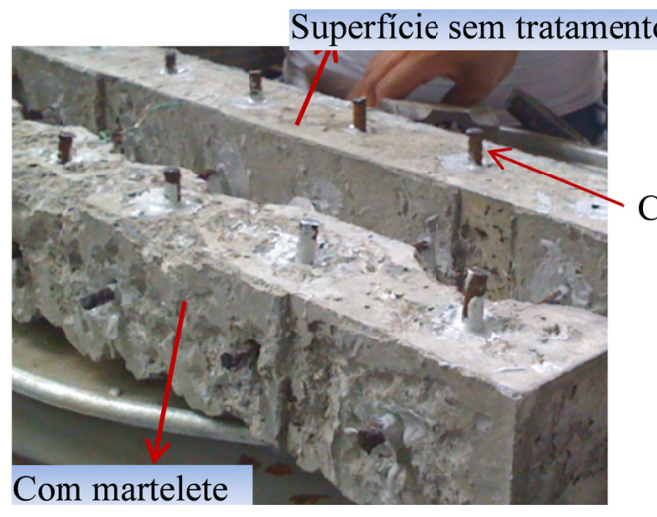

(a) Escarificação com martelete, e peça sem tratamento superficial

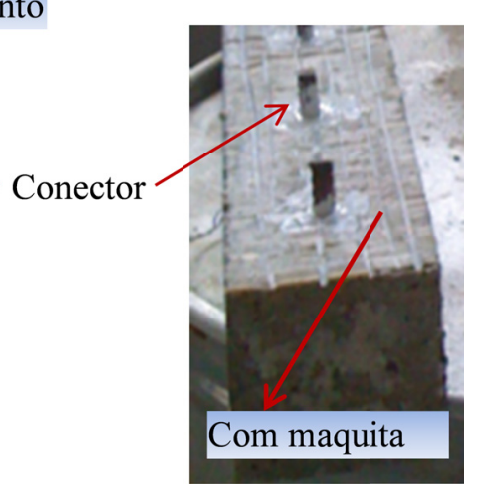

(b) Escarificação com serra circular.

Figura 8: Aspecto da superfície escarificada e posicionamento dos conectores.

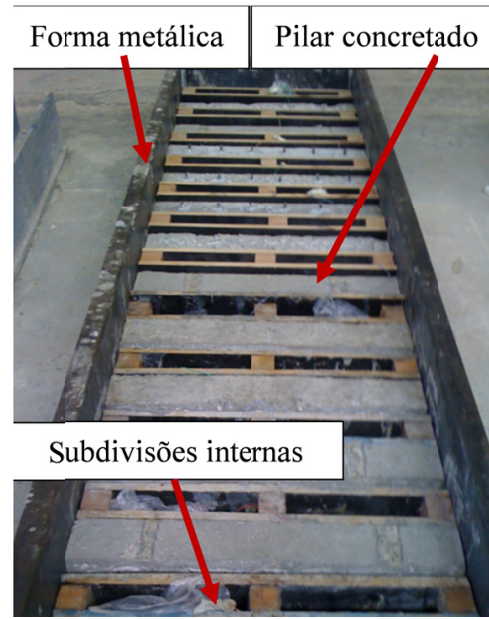

(a) Fôrma

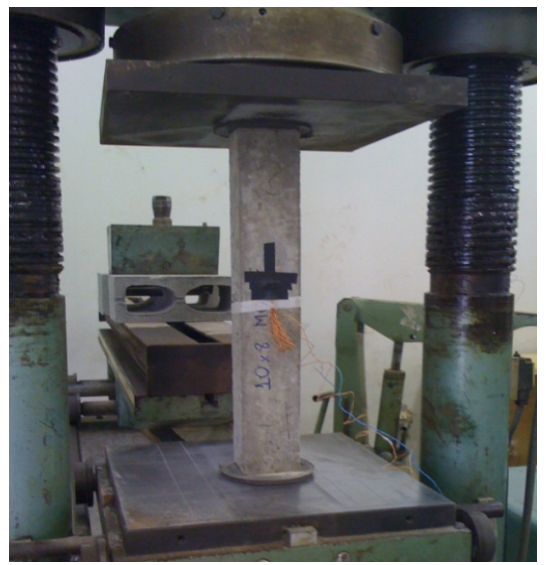

(b) Esquema de Ensaio - compressão centrada

Figura 9: Fôrma e Esquema de ensaio dos pilaretes.

\section{ANÁLISE DOS RESULTADOS}

Para prever a capacidade portante dos pilares utilizou-se a NBR 6118 (2003), admitindo-se compressão centrada, considerando pilar curto (esbeltez $\lambda \leq 40$ ) e a eq. 01 , simplificada. A previsão foi feita sem considera o coeficiente 0,85 do primeiro membro desta equação, pois este se refere ao efeito Rush, que considera as cargas atuantes nas estruturas como sendo de longa duração, mas como nos ensaios as cargas são de curta duração, seria inadequado considerá-lo na previsão da força de ruptura do pilar.

$$
\mathrm{N}_{\mathrm{d}}=0,85 \cdot f_{\mathrm{cd}} \cdot \mathrm{A}_{\mathrm{c}}+\mathrm{A}_{\mathrm{s}} \cdot f_{\mathrm{yd}}
$$

Onde:

$\mathrm{N}_{\mathrm{d}}$ : força normal de cálculo

$f_{c d}$ : resistência de cálculo do concreto à compressão;

$A_{c} ; A_{s}$ : área da seção transversal de concreto e área da armadura longitudinal ;

$f_{\text {yd }}$ : tensão de escoamento do aço utilizado na armadura longitudinal;
As cargas de ruptura teóricas e experimentais das peças monolíticas estão na Tabela 3. As cargas teóricas foram determinadas usando o concreto de menor resistência, pois é ele que limita a capacidade da peça. Por esta tabela percebe-se que as cargas de ruptura experimentais foram menores que as teóricas. Isso ocorreu porque a regularização das extremidades do pilarete, feita com capeamento de enxofre, não garantiu que as superfícies de contato da peça com a prensa ficassem paralelas, fazendo com que a força deixasse de ser axial, gerando momento fletor, e consequentemente uma ruptura prematura (ver Figura 10a).

A existência de falhas de adensamento (ver Figura 10b) também prejudicou a resistência dos pilares reforçados, principalmente dos que possuíam conector. Este dispositivo dificultou ainda mais a passagem do concreto do reforço por dentro da forma, devido ao pequeno espaço (apenas $2 \mathrm{~cm}$ ) e ao fato do concreto do reforço ter utilizado brita 1.

Na Tabela 4 e a Figura 11 apresentam uma comparação entre as resistências dos pilares reforçados 
em relação aos monolíticos. Por esta tabela observou-se que todos os reforços realizados conseguiram aumentara a capacidade portante em relação ao pilar original $8 \mathrm{~cm} x$ $8 \mathrm{~cm}$. Porém, as peças reforçadas usando conectores apresentaram desempenho aquém do esperado justamente pelo fato de ter ocorrido "ninhos" de concretagem por falhas de adensamento anteriormente comentada.

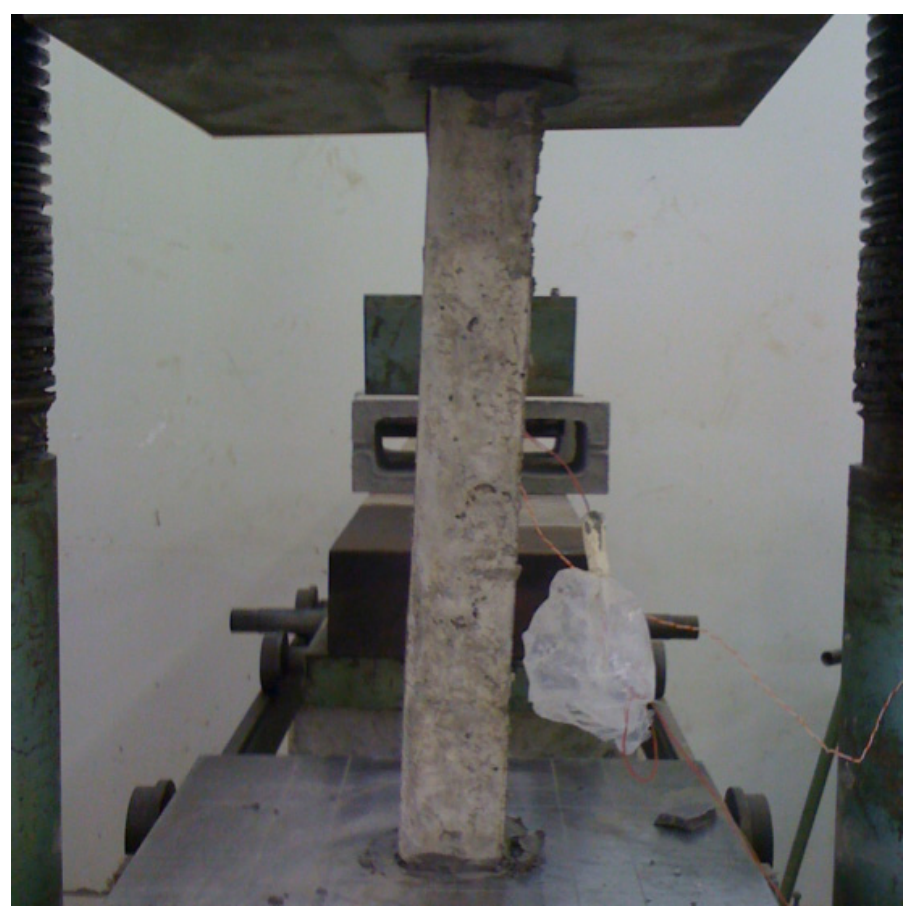

(a) Pilar fora do prumo

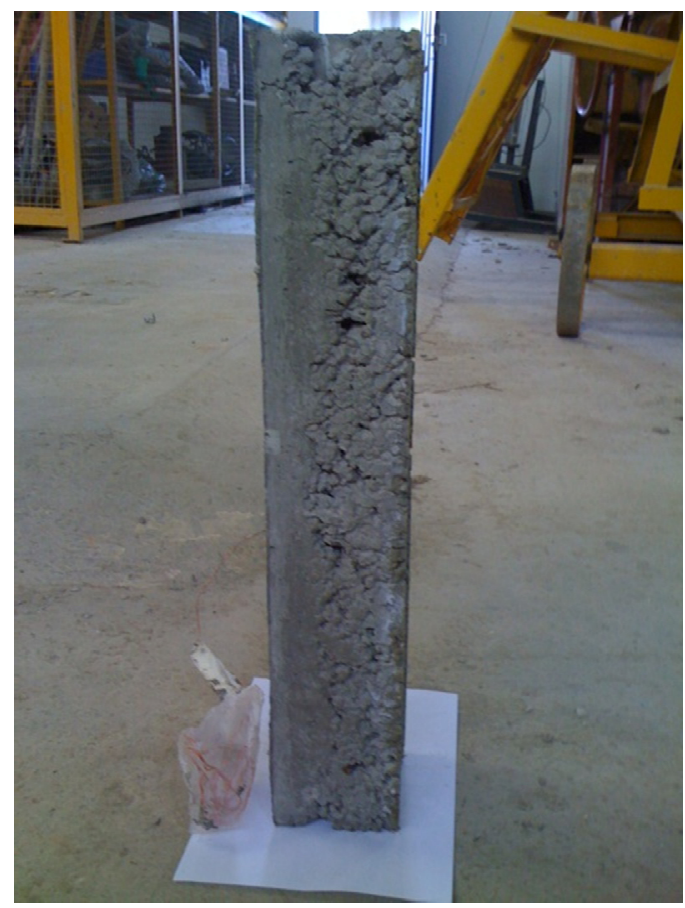

(b) Brocas de concretagem

Figura 10: Exemplos de problemas ocorridos durante o programa experimental.

\begin{tabular}{c|c|c|c}
\hline & \multicolumn{3}{|c}{ Tabela 3: Carga de ruptura dos pilares monolíticos } \\
\hline Pilar & $F_{\text {teo }}(\mathrm{kN})$ & $\mathrm{F}_{\text {exp }}(\mathrm{kN})$ & $\mathrm{F}_{\text {exp }} / \mathrm{F}_{\text {teo }}$ \\
\hline $8 \times 8 \mathrm{MO}$ & 361,0 & 121,0 & $34 \%$ \\
\hline $10 \times 8 \mathrm{MO}$ & 439,2 & 317,0 & $72 \%$ \\
\hline $10 \times 10 \mathrm{MO}$ & 537,0 & 312,5 & $58 \%$ \\
\hline $12 \times 10 \mathrm{MO}$ & 634,8 & 465,0 & $73 \%$ \\
\hline $12 \times 12 \mathrm{MO}$ & 752,2 & 610,0 & $81 \%$ \\
\hline
\end{tabular}




\begin{tabular}{|c|c|c|c|c|}
\hline Pilar & $\mathrm{F}_{\text {teo }}(\mathrm{kN})$ & $F_{\exp }(k N)$ & $F_{\text {exp }} / F_{10 \times 8 \text { Mо-ехр }}$ & $F_{\exp } / F_{10 \times 8 \text { Mo-teo }}$ \\
\hline $10 \times 8 \mathrm{MO}$ & 439,2 & 317,0 & - & - \\
\hline $10 \times 8$ STSC & - & 120,0 & $38 \%$ & $27 \%$ \\
\hline $10 \times 8$ STCC & - & 280,0 & $88 \%$ & $64 \%$ \\
\hline 10x8 MARTSC & - & 210,0 & $66 \%$ & $48 \%$ \\
\hline 10x8 MARTCC & - & 275,0 & $87 \%$ & $63 \%$ \\
\hline 10x8 MQCC & - & 358,0 & $113 \%$ & $82 \%$ \\
\hline Pilar & $\mathrm{F}_{\text {teo }}(\mathrm{kN})$ & $F_{\exp }(k N)$ & $F_{\exp } / F_{10 \times 10 M O-\exp }$ & $F_{\text {exp }} / F_{10 \times 10 \text { мо-teo }}$ \\
\hline $10 \times 10 \mathrm{MO}$ & 537,0 & 312,5 & - & - \\
\hline $10 \times 10$ STSC & - & 525,0 & $168 \%$ & $98 \%$ \\
\hline $10 \times 10$ STCC & - & 365,0 & $117 \%$ & $68 \%$ \\
\hline 10x10 MARTSC & - & 445,0 & $142 \%$ & $83 \%$ \\
\hline 10×10 MARTCC & - & 495,0 & $158 \%$ & $92 \%$ \\
\hline $10 \times 10 \mathrm{MQCC}$ & - & 385,0 & $123 \%$ & $72 \%$ \\
\hline Pilar & $\mathrm{F}_{\text {teo }}(\mathrm{kN})$ & $F_{\exp }(k N)$ & $F_{\text {exp }} / F_{12 \times 10 M 0-\exp }$ & $F_{\text {exp }} / F_{12 \times 10 \text { Mo-teo }}$ \\
\hline $12 \times 10 \mathrm{MO}$ & 634,8 & 465,0 & - & - \\
\hline $12 \times 10$ STSC & - & 600,0 & $129 \%$ & $95 \%$ \\
\hline $12 \times 10$ STCC & - & 450,0 & $97 \%$ & $71 \%$ \\
\hline 12X10 MARTSC & - & 700,0 & $151 \%$ & $110 \%$ \\
\hline 12X10 MARTCC & - & 420,0 & $90 \%$ & $66 \%$ \\
\hline $12 \times 10 \mathrm{MQCC}$ & - & 330,0 & $71 \%$ & $52 \%$ \\
\hline Pilar & $\mathrm{F}_{\text {teo }}(\mathrm{kN})$ & $F_{\exp }(k N)$ & $F_{\exp } / F_{12 \times 12 M 0-\exp }$ & $F_{\text {exp }} / F_{12 \times 12 M o-t e o}$ \\
\hline $12 \times 12 \mathrm{MO}$ & 752,2 & 610,0 & - & - \\
\hline $12 \times 12$ STSC & - & 540,0 & $89 \%$ & $72 \%$ \\
\hline $12 \times 12$ STCC & - & 525,0 & $86 \%$ & $70 \%$ \\
\hline $12 \times 12$ MARTSC & - & 485,0 & $80 \%$ & $64 \%$ \\
\hline 12X12 MARTCC & - & 515,0 & $84 \%$ & $68 \%$ \\
\hline $12 \times 12 \mathrm{MQCC}$ & - & 500,0 & $82 \%$ & $66 \%$ \\
\hline
\end{tabular}




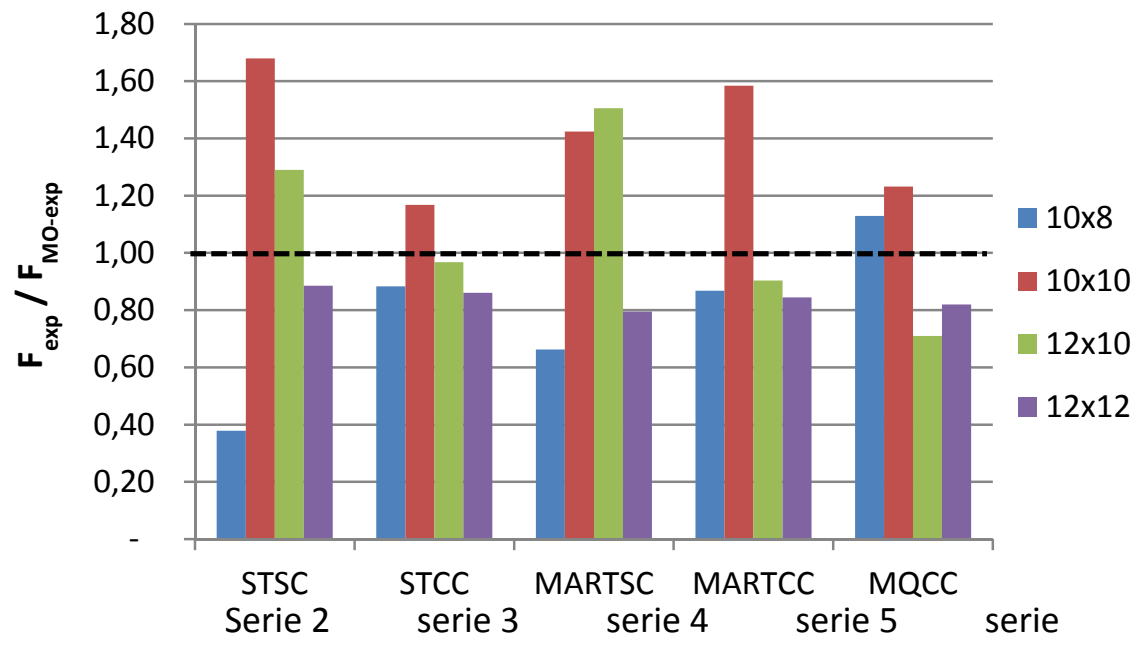

Figura 11: Gráfico da relação entre força de ruptura experimental dos pilares reforçados e força de ruptura experimental do pilar monolítico correspondente.

Comparando-se os pilares sem tratamento superficial em relação à presença de conectores nas faces reforçadas (série 2 e 3), constatou-se que, ao contrário do que se esperava, alguns pilares reforçados da série 2 apresentaram desempenho melhor que os da série 3. Acredita-se que isso tenha ocorrido devido as falhas de adensamento serem mais severas nos pilares dessa série, causando redução da capacidade portante das peças.

Comparando-se os pilares da série 4 e 5 , percebe-se que todas as peças da série 5 que possuía conector apresentaram melhor desempenho. A única exceção foram os pilares que possuíam seção $12 \times 10 \mathrm{~cm}$. Logo, pode-se concluir que a presença de conectores realmente melhora a resistência da peça combatendo as tensões tangenciais que surgem na interface do substrato com o reforço. Além disso, acredita-se que o fato da superfície ter sido escarificada usando martelete, a aderência entre os concretos tenha sido maior, o que minimizou a queda de resistência das peças com conector devido às falhas de adensamento.

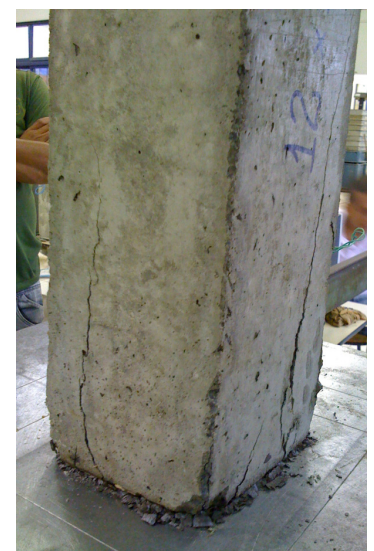

(a) esmagamento $(12 \times 12 \mathrm{~cm}$ MARTSC)

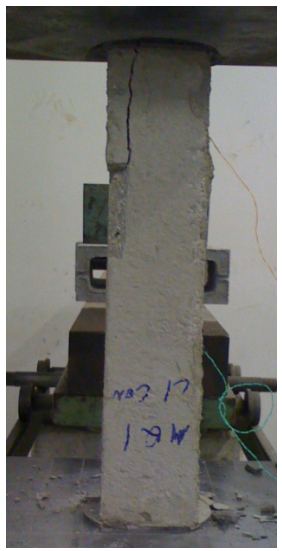

(b) desplacamento do reforço (12x10 cm MQCC)
Comparando-se os resultados da série $3 \mathrm{com}$ os da série 6 percebe-se que a escarificação usando serra circular não foi tão eficiente pois o ganho de resistência do pilar foi em alguns casos até inferior ao dos pilares sem tratamento na junta.

Quanto ao modo de ruptura, a maioria dos pilares apresentou esmagamento em suas extremidades (Figura 11a). Alguns pilares reforçados com conector apresentaram desplacamento parcial do concreto do reforço (Figura 11b), indicando falhas da aderência entre reforço e substrato. Já os pilares reforçados sem conector romperam bruscamente por desplacamento total da camada de reforço (Figura 11c) seguido de flambagem da armadura, sugerindo que a ausência de conectores tornaram a ruptura ainda mais frágil do que a observada nos demais pilares em que ocorreu apenas o desplacamento entre concretos. A série 6, que usou maquita, foi a que mais apresentou desplacamento do reforço, indicando que este tipo de tratamento realmente não foi tão eficiente quanto à escarificação feita usando martelete (série 5). 


\section{CONCLUSÕES}

- A técnica de reforço estudada foi eficiente, pois todas as peças reforçadas tiveram uma capacidade portante maior que a do pilar original $8 \times 8 \mathrm{~cm}$. Porém, mais estudos são necessários para definir o melhor tipo de tratamento superficial a ser aplicado, bem como a maneira de quantificar a posição e o espaçamento dos conectores a serem utilizar em pilares reforçados pela técnica de encamisamento.

- Dentre os tipos de tratamento dado à superfície, concluiu-se que a escarificação usando martelete pneumático foi a mais eficiente, e a escarificação feita usando serra circular (maquita) não foi tão eficiente quanto se esperava. No caso do martelete pneumático, é preciso cuidado para fazer a escarificação para que o equipamento não gere microfissuras no substrato, prejudicando ainda mais a resistência da peça a ser recuperada.

- Os conectores são fundamentais para combater as tensões tangenciais que surgem na interface do reforço com o substrato. Neste trabalho, os conectores não foram tão eficientes porque ocorreram "ninhos" de concretagem devido uso de um concreto inadequado para o tipo de serviço. Mesmo assim, o esquema de ruptura observado em vários pilares indicaram que nas peças sem conectores, a ruptura foi mais brusca e houve o desplacamento total da camada de reforço adicionada. Já nos pilares com conector, este desplacamento foi apenas parcial. Isso sugere a importância do uso destes conectores para garantir uma ruptura mais dúctil.

- Para garantir que as faces de contato do pilar ensaiado com a prensa fiquem paralelas, e que a compressão dos pilaretes seja realmente centrada, recomenda-se que nos trabalhos futuros seja feita uma retificação das superfícies de contato, e não seu capeamento usando enxofre.

\section{AGRADECIMENTOS}

Os autores agradecem a CAPES e ao CNPq pelo financiamento concedido, às empresas Carlos Campos Consultoria, Impercia e Realmix, pela doação de materiais e apoio técnico prestado na execução dos ensaios, bem como aos técnicos do Laboratório de Materiais e do Laboratório de Estruturas da EEC-UFG.

\section{REFERÊNCIAS BIBLIOGRAFIAS}

ABNT: Associação Brasileira de Normas Técnicas. NBR 6118:2003 - Projeto de estruturas de concreto - Procedimento. Rio de Janeiro, 2003.
ALI, M. A.,WHITE, R. N. Enhanced contact model for shear friction of normal and high strength concrete. ACl Structural Journal, v. 96, n. 3, p. 348-362, jun. 1999.

CARASEK, H. Aderência de Argamassa à Base de Cimento Portland a Substratos Porosos - Avaliação dos Fatores Intervenientes e Contribuição ao Estudo do Mecanismo de Ligação. 1996. Tese (Doutorado) EPUSP - Universidade de São Paulo. São Paulo, 1996.

NASCIMENTO, P. P. Análise Experimental de Piares de Concreto Armado Submetidos à Flexo-Compressão, Reforçados com Concreto Auto-Adensável e Conectores. Dissertação (Mestrado), UFG, Goiânia, Goiás, 2009.

OMAR, M. Y. M. Análise Experimental de Pilares de Concreto Armado Reforçados com Concreto Auto-Adensável (CAA). Dissertação (Mestrado), UFG, Goiânia, Goiás, 2006.

SAHB, K. F. P. Análise Experimental de Pilares de Concreto Armado Submetidos à Flexo-Compressão, Reforçados com Concreto Auto-Adensável e Chumbadores. 224f. Dissertação (Mestrado) UFG, Goiânia, Goiás, 2008.

TAKEUTI, A. R. Reforço de Pilares de Concreto Armado por Meio de Encamisamento com Concreto de Alto Desempenho. 1999. 184f. Dissertação (Mestrado). USP, São Carlos. 